Terzella, S. '; Barbudo-Selmi, G.R. 2; Banks, A.G.'; Selmi, A.L. ${ }^{3}$; Lins, B.T. ${ }^{4} ;$ Simões, A. ${ }^{5}$

\section{1 - Emprego de n-butil-cianoacrilato associado ou não à sutura na síntese de gastrotomias em ratos (Rattus norvegicus)}

1- Graduando da FAV - Universidade de Brasilia, Brasília-DF

2- Doutorando da Faculdade de Ciências Agrárias e Veterinárias da Universidade Estadual Paulista (UNESP), Jaboticabal-SP

3- Professor da Faculdade Anhembi Morumbi, São Paulo-SP

4- Residente da Faculdade de Medicina Veterinária de Araçatuba (UNESP), Araçatuba-SP

5- Médico Veterinário Autônomo

Os adesivos cirúrgicos à base de cianoacrilato têm sido intensamente empregados na prática veterinária, tanto em dermorrafias como em procedimentos cirúrgicos internos. Dentre os agentes deste grupo, os de radical butila são os mais utilizados por sua baixa toxicidade e boa aderência. A utilização desses compostos constitui uma alternativa como meio de se diminuir o tempo cirúrgico em muitos procedimentos. O presente estudo avaliou os efeitos do emprego do adesivo n-butil-cianoacrilato associado ou não a sutura na síntese de gastrotomias em ratos (Rattus norvegicus). Foram utilizados 48 ratos, linhagem Wistar, com peso médio de $0,214 \mathrm{~kg}$ e 90 dias de idade. Os animais foram submetidos à jejum hídrico e alimentar de 2 horas e posteriormente foram anestesiados utilizando-se associação de xilazina $(5 \mathrm{mg} / \mathrm{kg}) \mathrm{e}$ cetamina $(25 \mathrm{mg} / \mathrm{kg})$ por via intramuscular. Todos animais receberam butorfanol $(0,2 \mathrm{mg} /$ $\mathrm{kg}, \mathrm{IM}, \mathrm{BID})$ e cefazolina sódica $(20 \mathrm{mg} / \mathrm{kg}, \mathrm{IM}, \mathrm{BID})$ antes do procedimento cirúrgico e por 3 dias consecutivos. No período pós-operatório foi realizado jejum hídrico e alimentar de 24 horas e retorno gradual à alimentação sólida. Os animais foram divididos conforme o tipo de síntese gástrica em grupo CS (utilização do adesivo cirúrgico associado à sutura) e grupo C (somente emprego de adesivo). Duas gotas do adesivo foram aplicadas sobre as bordas da parede gástrica aproximadas por uma pinça de Cushing. Os animais de ambos os grupos foram subdivididos e eutanasiados aos 3, 7, 14 e 21 dias após o procedimento cirúrgico. O fragmento gástrico contendo a sutura foi seccionado por guilhotina manual, com lâminas dispostas a cada um centímetro, de forma a minimizar a variação na largura da amostra. A força tênsil da amostra (Newton/força) foi analisada em tensiômetro digital (Versa Test Mecmesin) na velocidade de $100 \mathrm{~mm} / \mathrm{min}$. Os resultados foram analisados pelo teste do $t$ de Student, sendo apresentados como média e desvio-padrão, considerando-se $\mathrm{p}<0,05$. Excetuando-se os animais analisados aos três dias após a cirurgia, quando a força tênsil foi mais elevada com o emprego do adesivo cirúrgico associado à sutura, não houve diferenças entre os grupos (Tabela 1). Apesar da ocorrência de deiscência cirúrgica não ter sido observada em nenhum animal, a incidência de aderências abdominais decorrentes do emprego do adesivo cirúrgico foi significativamente mais elevada após uso isolado do adesivo cirúrgico quando comparado à associação à sutura (Tabela 2). O emprego isolado de n-butilcianoacrilato mostrou ser um método eficiente na sintese de tecidos biológicos, porém seu uso parece ser contra-indicado na sintese de gastrotomias. Um ganho de força tensil inferior na fase pós-operatória imediata pode predispor a deiscência da ferida cirúrgica e consequeencias desastrosas decorrentes da contaminação da cavidade abdominal. O elevado índice de aderências também constitui um fator negativo na utilização dessa técnica quando comparado à utilização de sutura. $\mathrm{O}$ emprego associado deste adesivo cirúrgico à sutura possibilita significativa redução na incidência destas complicações pós-cirúrgicas, e relativa diminuição do tempo operatório quando comparada às técnicas tradicionais utilizando dois padrões de sutura. 